\title{
Physical versus Synthetic Exchange Traded Funds. Which One Replicates Better?
}

\author{
Cesario Mateus ${ }^{1}$, Yana Rahmani ${ }^{2}$ \\ ${ }^{1}$ Centre for Governance, Risk and Accountability, University of Greenwich, London, United Kingdom \\ ${ }^{2}$ Department of Accounting and Finance, University of Greenwich, London, United Kingdom \\ Email: c.mateus@greenwich.ac.uk
}

How to cite this paper: Mateus, C. and Rahmani, Y. (2017) Physical versus Synthetic Exchange Traded Funds. Which One Replicates Better? Journal of Mathematical Finance, 7, 975-989.

https://doi.org/10.4236/jmf.2017.74054

Received: October 14, 2017

Accepted: November 26, 2017

Published: November 29, 2017

Copyright ( 92017 by authors and Scientific Research Publishing Inc. This work is licensed under the Creative Commons Attribution International License (CC BY 4.0).

http://creativecommons.org/licenses/by/4.0/

\section{(c) (i) Open Access}

\begin{abstract}
This paper investigates the tracking performance of physical and synthetic equity exchange traded funds listed (ETFs) on the London Stock Exchange (LSE) during the period 2008 to 2013. We examine the ETFs accuracy in replicating their benchmark returns, with different geographical focus, applying several tracking metrics and including the financial crisis period. First, we did not find evidence that synthetic ETFs outperformed physical ETFs in terms of lower daily tracking performance. Second, the results show that the ability of ETFs to replicate its benchmark index's returns depends on characteristics of the securities composing the index. Third, we provide evidence that the 2008-2009 financial crises had negative impact on daily tracking performance for all ETFs. Fourth, the method to estimate the tracking error impacts the results.
\end{abstract}

\section{Keywords}

Exchange-Traded Funds, Synthetic and Physical ETFs, Tracking Error, Tracking Difference

\section{Introduction}

Exchange-traded funds (ETFs) are considered a cost-efficient way to access a multiplicity of investment exposures and hence have increased popularity among investors after their first introduction on the New York Stock Exchange in 1993. Over the years new and advanced versions of ETFs have been developed such as the introduction of synthetic ETFs in Europe in 2001. Essentially, ETFs are the baskets securities that seek to replicate the performances of their benchmark indices by holding the indices securities or by entering into swap agreements. Thus, ETF's shares offer the exposure to an entire index or a fund to an 
investor. However, even though ETFs are designed to replicate their benchmark indices none of them can do it perfectly. There is basically to ways to measure the tracking performance of ETFs: tracking difference and tracking error. Differences arise between ETFs' and benchmark's returns for a variety of reasons and two of most common the redemption/creation processes and replication methodology. It is argued that one of the main sources of tracking error is expense ratios ([1] [2] [3]). And empirical results indicate that tracking error is negatively associated to the fund's expense ratio. Thus, larger tracking error is produced by the fund with higher expense ratio. However, [4] point out that expense ratio has an impact only on tracking difference. This is because total expense ratio usually stays constant over the calculation's time period (no volatility). Consequently, tracking error is not affected by expense ratio, because tracking error measures the volatility of the difference between the ETF's and the benchmark index's returns.

[5] and [6] study the effect of asynchronous trading across international time zones on country ETFs listed on U.S. exchanges. [5] find that time zone difference only partly explains the difference between the ETFs' performance and the benchmark indices' performance. [6] reveals that the more the hours the foreign exchanges overlap with the operating hours of U.S. exchanges, the higher the correlation between ETFS and their benchmark indices.

[7] investigate the influence of dividends, spreads of trading prices and exchange rate on tracking error. They find that only exchange rate is a statistically significant factor. An increase in the exchange rate corresponds to a depreciation of the U.S. dollar, thereby, increasing the ETF's NAV. As a result, the dispersion between the ETF's NAV and its benchmark is larger. [4] [8] [9] [10] claim that during the time of market stress, the ability of ETFs that replicate their benchmark indices is reduced. For example, [10] finds that Asian crisis in late 1998 and 1999 had an impact on the i Shares Malaysia. Meanwhile, [8] argue that the global financial crisis of 2008-2009 significantly affected the tracking errors across all ETFs traded on U.S. exchanges. The authors argue that during financial crisis bid-ask spreads are higher, trading volumes are lower. Thus, the creation and redemption process become costly and risky that negatively influences the ability of the ETFs to replicate their benchmark indices.

Additionally, [4] and [9] find that replication methodology affect tracking performance. [4] argue that ETFs using synthetic replication exhibit better tracking performance relative to ETFs using physical replication. This is because ETFs using synthetic replication do not incur experience cash drag (no dividends) and trading costs.

In this paper we examine the tracking performance of physical and synthetic equity exchange traded funds listed (ETFs) on the London Stock Exchange (LSE) during the period 2008 to 2013.

This study aims to contribute to the existing literature on exchange traded funds and tracking performance in several ways. First, to our knowledge, it is the 
first research analysing the tracking performance of equity ETFs listed on the London Stock Exchange. This will shed light to the ETFs accuracy in replicating their benchmark returns in the second largest world financial market. Second, we apply different methods to estimate the tracking error and tracking performance. Third, this research will test whether the ability of ETFs to replicate its benchmark index's returns depends on characteristics of the securities composing the index. Fourth, we control for the possible 2008-2009 financial crises effect on track performance.

The results can be summarized as follows. First, we did not find evidence that synthetic ETFs outperformed physical ETFs in terms of lower daily tracking performance. Second, the results show that the ability of ETFs to replicate its benchmark index's returns depends on characteristics of the securities composing the index. Third, we provide evidence that the 2008-2009 financial crises had negative impact on daily tracking performance for all ETFs. Fourth, the method to estimate the tracking error impacts the results. Finally, the method to estimate the tracking error impacts the results.

The rest of the paper is organized as follows. The next section discusses the theoretical framework and empirical evidence on exchange traded funds and tracking performance Section 2 presents the data sources and discusses sample selection and methodology implemented. In Section 4 we test the different daily tracking error metrics and present the results of this paper and Section 5 concludes the study.

\section{Data and Methodology}

\subsection{Sample and Data Collection}

The List of ETFs listed on the LSE is obtained from the official website of the LSE as of June 6, 2014. The sample of ETFs is restricted to Equity ETFs that track FTSE indices and for the period January 2008 to December 2013. The ETFs asset classes and benchmark indices are obtained from Bloomberg and the ETFs' replication method dividend policy, NAV, shares outstanding, trading volume and total expense ratios are obtained from the official websites of the ETFs' providers. Daily ETFs prices ${ }^{1}$ are collected from Datastream and daily indices total values (with declared dividends reinvested) are collected from the official website of FTSE. The final sample consists of 64 ETFs.

Table 1 presents the number of ETFs by issuers and the ETFs benchmark indices. The sample includes 64 ETFs from 16 different issuers. DB X-Trakers, Vanguard Funds plc and Powershares Global Funds Irland plc have the largest number of ETFs, roughly half of the total sample. The ETFs track 34 FTSE indices.

Each ETF is classified by its geographical focus defined by the benchmark index and divided into six categories: United Kingdom ETFs (U.K. ETFs), Europe

If an ETF distributes dividends, ETFs prices are adjusted for the dividend distributions on the ex-dividend date. 
Table 1. List of ETF's issuers and benchmark indices.

\begin{tabular}{|c|c|c|c|c|c|}
\hline ETF's Issuer & $\begin{array}{l}\mathrm{Nr} \text { of } \\
\text { ETFs }\end{array}$ & Benchmark Indices & Number & Benchmark Indices & Number \\
\hline AMUNDI ETF & 3 & FTSE 100 Daily Leveraged Index & 1 & $\begin{array}{l}\text { FTSE Ja Benchmark Indices } \\
\text { Benchmark Indices pan Index }\end{array}$ & 2 \\
\hline DB X-TRACKERS & 13 & FTSE 100 Index & 11 & FTSE MIB Index & 3 \\
\hline GO UCITS ETF SOLUTIONS PLC & 1 & FTSE 100 Minimum Variance & 1 & FTSE RAFI All-World 3000 Index & 1 \\
\hline HSBC ETFS PLC & 4 & FTSE 100 Short Daily Index & 1 & $\begin{array}{l}\text { FTSE RAFI Asia Pacific } \\
\text { Ex-Japan USD index }\end{array}$ & 1 \\
\hline ISHARES II PLC & 1 & FTSE 250 Index & 5 & FTSE RAFI Developed 1000 index & 1 \\
\hline ISHARES PLC & 5 & FTSE All-Share Index & 3 & $\begin{array}{l}\text { FTSE RAFI Developed Europe } \\
\text { Mid-Small index }\end{array}$ & 1 \\
\hline ISHARES VII PLC & 3 & FTSE ALL-WORLD Ex UK Index & 1 & $\begin{array}{l}\text { FTSE RAFI Emerging } \\
\text { Markets Index }\end{array}$ & 1 \\
\hline $\begin{array}{l}\text { LYXOR INTERNATIONAL } \\
\text { ASSET MANAGEMNT }\end{array}$ & 2 & $\begin{array}{l}\text { FTSE All-World High } \\
\text { Dividend Yield Index }\end{array}$ & 2 & FTSE RAFI Europe index & 1 \\
\hline MULTI UNITS FRANCE & 5 & $\begin{array}{l}\text { FTSE All-World High } \\
\text { Dividend Yield Index }\end{array}$ & 2 & $\begin{array}{l}\text { FTSE RAFI Hong Kong } \\
\text { China index }\end{array}$ & 1 \\
\hline OSSIAM LUX & 1 & FTSE All-World Index & 2 & FTSE RAFI UK 100 index & 1 \\
\hline $\begin{array}{l}\text { POWERSHARES GLBAL } \\
\text { FUNDS IRELAND PLC }\end{array}$ & 9 & FTSE China 25 Index & 2 & FTSE RAFI US 1000 Index & 1 \\
\hline SOURCE MARKETS PLC & 2 & FTSE Coast Kuwait 40 index & 2 & FTSE UK Dividend+ & 2 \\
\hline SSGA SPDR ETFS EUROPE I PLC & 1 & $\begin{array}{l}\text { FTSE Developed Asia } \\
\text { Pacific ex Japan Index }\end{array}$ & 2 & FTSE Vietnam index & 2 \\
\hline UBS ETF & 1 & FTSE Developed Europe Index & 1 & FTSE/JSE TOP 40 index & 2 \\
\hline UBS ETFS PLC & 1 & FTSE Emerging Index & 2 & FTSE/NAREIT Developed index & 2 \\
\hline \multirow[t]{3}{*}{ VANGUARD FUNDS PLC } & 12 & $\begin{array}{l}\text { FTSE EPRA/NAREIT } \\
\text { Developed Europe Index }\end{array}$ & 1 & FTSEurofirst 100 Index & 1 \\
\hline & & $\begin{array}{c}\text { FTSE EPRA/NAREIT } \\
\text { Developed Europe Net TR Index }\end{array}$ & 1 & FTSEurofirst 80 Index & 1 \\
\hline & & $\begin{array}{l}\text { FTSE EPRA/NAREIT } \\
\text { Global Net TR index }\end{array}$ & 2 & & \\
\hline
\end{tabular}

ETFs, global ETFs, country ETFs, Emerging markets ETFs and Asian Pacific region excluding Japan ETFs. An ETF is defined as U.K. ETF if more than $80 \%$ of the securities in its benchmark index are the U.K. securities. An ETF is classified as Europe ETF if its benchmark index comprises the securities from the following counties: France, Germany, Spain, Netherlands, Italy, Belgium, Finland and others. An ETF is defined as global ETF if the securities in its benchmark index are issued in different countries, such as United States, Japan, Hong Kong, Australia, Singapore, France, China, Canada and others. An ETF is classified as a country ETF if more than $80 \%$ of the securities in its benchmark index are issued in one country, excluding United Kingdom, China, South Africa, Kuwait, and Vietnam. The ETFs whose benchmark indices comprise the securities from 
China, South Africa, Kuwait, Vietnam, Taiwan, India, Russia, Mexico, Malaysia, Indonesia, and Thailand are defined as emerging markets ETFs. Finally, Asian Pacific region ETFs includes the ETFs that track indices with securities from Australia, South Korea, Hong Kong, Singapore, New Zealand, excluding Japan.

Additionally, each ETF is categorized based on replication methodology. Table 2 shows the number of ETFs in the sample regarding their geographical focus and replication methodology. Although all ETFs in the sample are traded on the LSE, the securities in the benchmark indices are often non-U.K. For instance, only twenty four out of sixty four ETFs track benchmark indices with exclusively of U.K. securities. Forty two out of sixty four ETFs are physical. The rest of the ETFs in the sample are synthetic.

\subsection{Methodology}

\subsubsection{Tracking Error Calculation}

ETF's performance can be measure either by their NAV or market prices. It is suggested that the tracking error estimated by the NAV just reflects the fund manager performance, while the market price reflect the supply and demand of ETF's shares in addition to the efficiency of the creation and redemption processes ([8]). Since this paper is focused on the ETF ability to replicate their benchmark indices tracking error is measured by ETF's market price inclusive of distributions.

We first compute the daily ETFs and indices returns for each of the ETF in the sample. The daily ETF's return is computed as a natural logarithm of the current period ETF's price, inclusive of distributions, divided by the previous-period ETF's price, inclusive of distributions. The daily index's return is computed as a natural logarithm of the current period index's price, with declared dividend reinvested, divided by the previous-period index's price, with declared dividend reinvested. The length of ETFs and indices return history varies due to data availability. We calculate the tracking error as:

$$
T E_{i, t}=E T F_{i, t}-\text { Index }_{i, t}
$$

where, $T E_{i, t}$ is the tracking error for ETF $i$ at time $t, E T F_{i . t}$ is the ETF return of ETF $i$ at time $t$ and Index is the return on the respective index $i$ at time $t$.

In a second step, two daily tracking error metrics are calculated for each ETF in the sample per calendar year, the average daily absolute tracking error and the standard deviation of daily tracking error ([7]) as:

Table 2. Geographical focus and replication method.

\begin{tabular}{ccccccc}
\hline $\begin{array}{c}\text { Replication } \\
\text { Method }\end{array}$ & $\begin{array}{c}\text { United } \\
\text { Kingdom }\end{array}$ & Europe & Global & $\begin{array}{c}\text { Country } \\
\text { ETFs }\end{array}$ & $\begin{array}{c}\text { Emerging } \\
\text { Markets }\end{array}$ & $\begin{array}{c}\text { Asian Pacific } \\
\text { Region ex Japan }\end{array}$ \\
\hline Physical & 14 & 6 & 9 & 7 & 3 & 3 \\
Synthetic & 10 & 1 & 3 & --- & 8 & --- \\
Total & 24 & 7 & 12 & 7 & 11 & 3 \\
\hline
\end{tabular}




$$
\overline{T E}_{i}=\frac{\sum_{t=1}^{n}\left[E T F_{i, t}-\text { Index }_{j, t}\right]}{n}
$$

where, $\overline{T E}_{i, t}$ is the average daily absolute tracking error for ETF $i, E T F_{i . t}$ is the ETF return of ETF $i$ at time $t$, Index is the return on the respective index $j$ at time $t$ and $n$ is the number of daily returns.

$$
\sigma_{T E_{i}}=\sqrt{\frac{\sum_{t=1}^{n}\left(T E_{i, t}-\overline{T E}_{i}\right)^{2}}{n-1}}
$$

where, $\sigma_{T E_{i}}$ standard deviation of daily tracking error, $T E_{i, t}$ is the tracking error of ETF $i$ at time $t, \overline{T E}_{i, t}$ is the average daily absolute tracking error for ETF $i$ and $n$ is the number of daily returns.

Finally, we calculate per year the tracking differences between the ETFs sample and the benchmark indices. It is considered that tracking error does not capture the actual performance of an ETF relative to its benchmark index. For this reason, an investor should consider tracking error and tracking difference when evaluating an ETF's tracking performance ([4]). The tracking difference is defined as the annual ETF's return minus the annual index's return ([8]):

$$
\Delta E T F_{i}=A E T F_{i}-\text { Alndex }_{j}
$$

where, $\triangle E T F_{i}$ is the annual tracking difference, $A E T F_{i}$ is the annual return on ETF $i$ and AIndex $i$ is the annual return on the respective index $j$.

\subsubsection{Regression Analysis}

It is important to measure how closely daily ETF's returns mimic return variation in its benchmark index. For this reason, the next step of the analysis is to estimate regression where the linear association between an ETF's returns and it benchmark index' returns is calculated. If the daily ETFs' returns perfectly replicate the benchmark index's return, it is expected that coefficient estimated to be close to one. The following regression is performed:

$$
E_{T F}=\alpha_{i}+\beta_{1} \operatorname{Index}_{j, t}+\varepsilon_{i, t}
$$

where, $E_{T F}$ and Index $_{j, t}$ are the ETF $i$ and Index $_{j}$ returns at time $t$, respectively, $\alpha$ is the constant term, $\beta_{1}$ the estimated coefficient and $\varepsilon_{i, t}$ the error term.

\section{Results}

\subsection{Daily Tracking Error}

We start by presenting average values for the two daily tracking metrics for the ETFs per year, replication method and geographical focus in Figures 1-4.

Across all observations, the average of the average absolute tracking error is 58 basis points (bps). However, tracking errors vary over the sample period and across ETFs' categories. The smallest average value are from U.K. ETFs (21 bps) and the largest average values from emerging markets ETFs (102 bps), Asian ${ }^{2}$ The full tables are available upon request. 


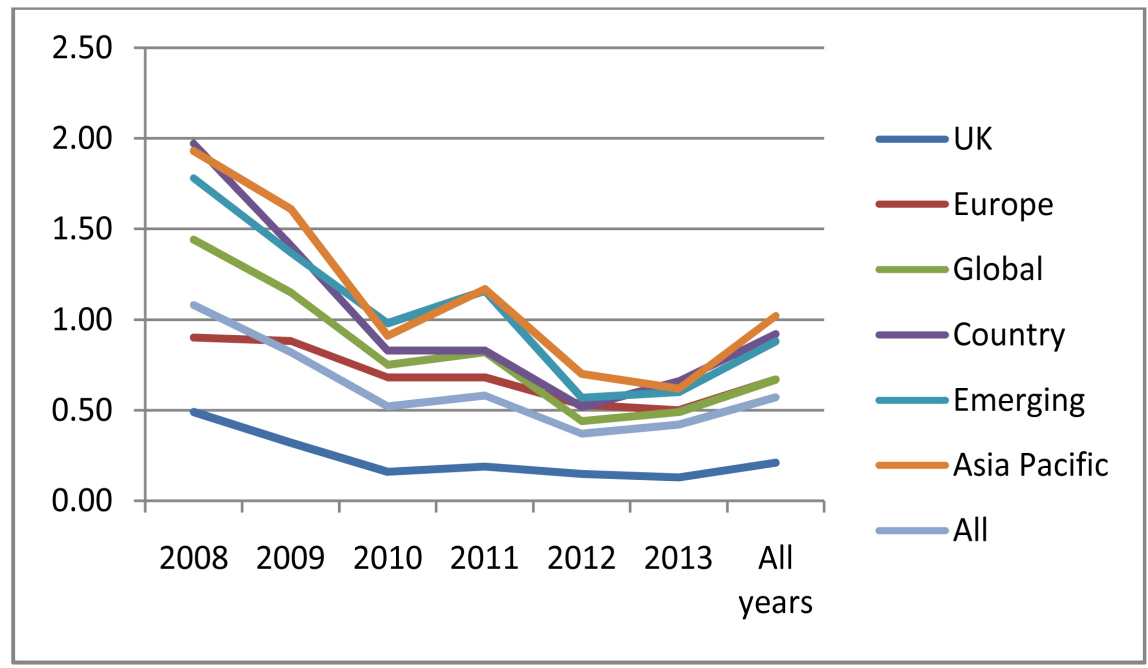

Figure 1. Average daily tracking error (physical ETF).

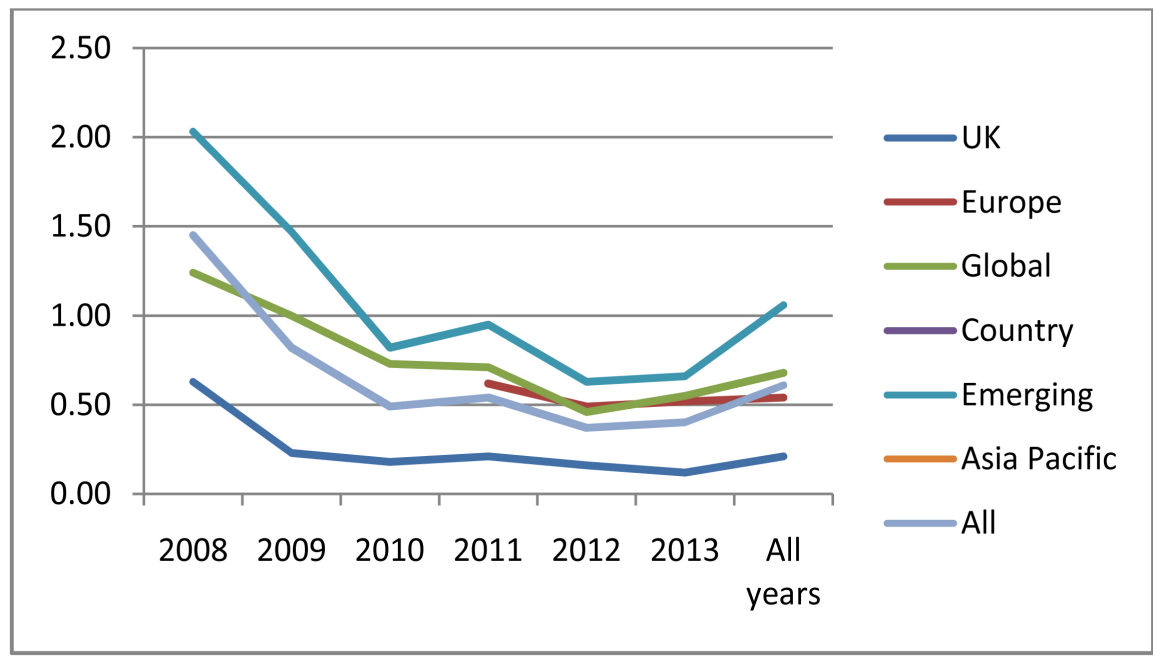

Figure 2. Average daily tracking error (Synthetic ETF).

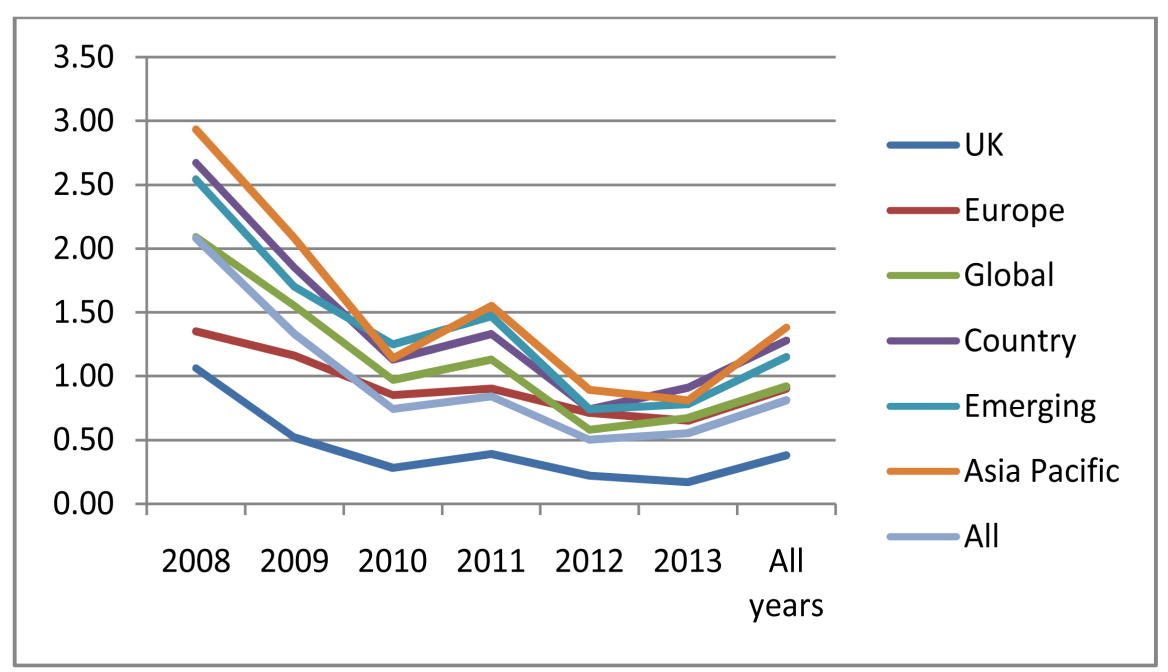

Figure 3. Standard deviation of daily tracking error (Physical ETF). 


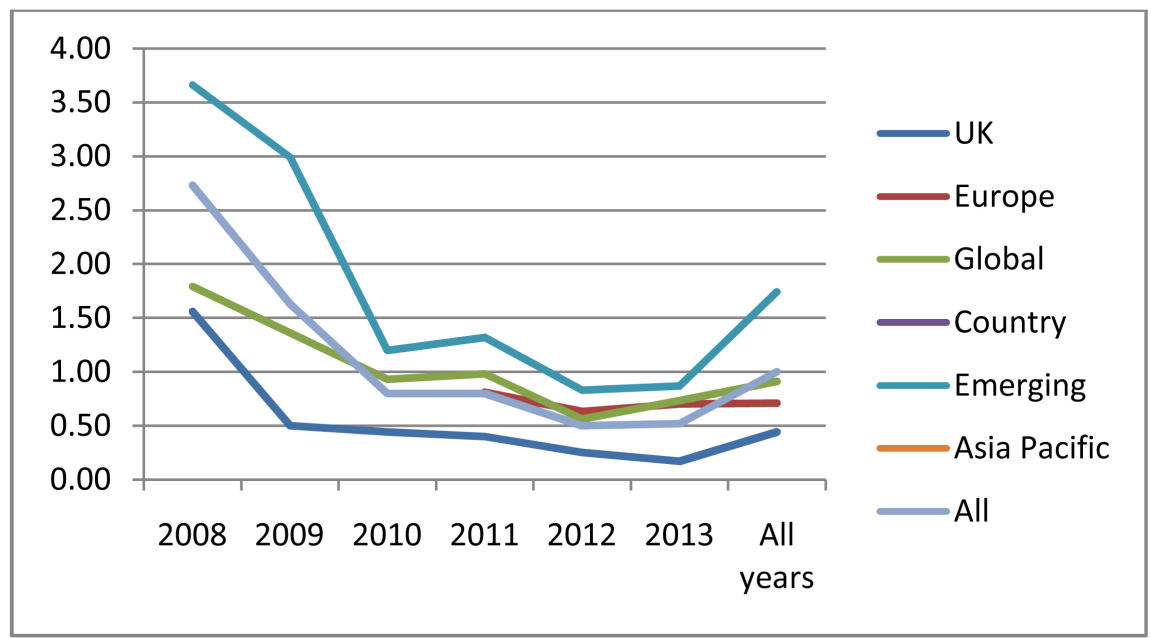

Figure 4. Standard deviation of daily tracking error (Synthetic ETF).

Pacific region ETFs (102 bps), and country ETFs (92 bps). Europe ETFs (66 bps) and global ETFs (67 bps) exhibit slightly lower average of the absolute daily tracking errors compared to emerging markets ETFs, country ETFs, and Asian Pacific region ETFs. These findings are consistent with the findings of [4] [5] [7] [8] [11] [12] [13]. For example, [8] find that equity U.S. ETFs that track indices of U.S. securities exhibit lower tracking error for the period from 1994 to 2010 (24 bps) than non-U.S. securities indices trackers (88 bps). In addition, [13] reveals that domestic equity ETFs exhibit lower tracking error (47 bps) than international equity ETFs which exhibits larger tracking errors (113 bps).

The average of the standard deviation of daily tracking errors is consistent with the average of the absolute tracking errors results. However, this method of measurement of the ETFs' daily tracking performance indicates that all ETFs in the sample exhibit even larger tracking errors. This finding demonstrates that using different methods to estimate tracking errors can result in different tracking errors. Thus, investors using tracking errors, tracking differences from the official websites of the ETFs' providers should consider this fact.

Across all observations, the average of the standard deviation of daily tracking errors is 88 bps. U.K. ETFs (40 bps) exhibit the smallest standard deviation of daily tracking errors. Country (128 bps), emerging markets (162 bps) and Asian Pacific ETFs (138 bps) display the largest average values. These results are in line with the results of [3] [8]. [8] find that the median of the standard deviation of daily tracking errors of U.S. equity ETFs that track U.S. securities indices is substantially lower than non-U.S. securities trackers, 35 and 119 bps, respectively.

Moreover, during the financial crisis the ability of the ETFs in the sample to replicate their benchmark indices had been diminished. For example, across all ETFs in the sample, the mean of the average absolute daily tracking errors is 122 bps in 2008 and 82 bps in 2009, although the average values exhibit substantial variations across ETFs' geographical categories. UK. ETFs (54 and 28 bps in 2008 and 2009, respectively) exhibit the smallest daily tracking errors even dur- 
ing financial crisis. These findings are in line with the findings of [4] [8] [9] [10] [11]. This period of time was characterized by large bid-ask spreads, small trading volumes, and high volatility of currencies and exchange rates. All these together made the creation and redemption process costly and risky. For these reasons, tracking errors were larger during the financial crisis. The daily tracking performance of the ETFs has improved significantly after the financial crisis of 2008-2009. Across all observations in 2013, the mean of the average absolute daily tracking errors was 41 bps. U.K. ETFs (13 bps) shows the smallest daily tracking errors. The largest values still come from country (66 bps), emerging market (65 bps), and Asian Pacific region excluding Japan ETFs (62 bps). Thus, equity ETFs listed on the LSE that track indices of non-U.K. securities tend to have larger daily tracking errors than U.K. securities ETFs trackers. There are several possible explanations for the poor daily tracking performance of the indices of non-U.K. securities ETFs trackers. Firstly, [5] and [6] find that the differences between the performance of country ETFs, international ETFs, Asian ETFs and the performance of their benchmark indices tend to be larger due to the difference between time zones. For example, many Asian markets are closed during LSE opening hours. That is why some ETFs may respond with some delay to the changing in their benchmark indices. Secondly, [7] find that exchange rate volatility has a significant impact on the country level of tracking error. For example, ETFs that are traded in U.S. dollars shows lower daily tracking errors and tracking differences relative to the ETFs traded in U.K. pounds. Additionally, [4] [5] [7] [8] [12] find that the creation and redemption process of country ETFs, international ETFs, and emerging market ETFs is more complex due to taxes and other obstacles to trade. For these reasons, tracking errors of global ETFs, Europe ETFs, country ETFs, emerging market ETFs, and Asian Pacific region ETFs tend to be larger.

Additionally, it is compared tracking errors between physical and synthetic replication. Across all sample, ETFs using synthetic replication do not exhibit better daily tracking performance relative to ETFs using physical replication, although the daily tracking errors vary significantly over time and across ETFs' categories. For example to 2013, U.K. ETFs using synthetic replication shows slightly better daily tracking performance relative to the physical replication. Our findings are inconsistent with the results of [4] who find that tracking errors of synthetic ETFs are 30 bps lower than tracking errors of physical ETFs, on average. [4] claim that synthetic ETFs exhibit lower tacking errors because synthetic ETFs are cheap and do not pay dividends. However, emerging markets ETFs using synthetic replication exhibit larger tracking errors, perhaps because all emerging markets ETFs using synthetic replication in the sample track very small indices (FTSE China 25 Index, FTSE/JSE TOP 40 index, FTSE Vietnam index, FTSE Coast Kuwait 40 index).

\subsection{Tracking Difference}

Table 3 (Panels A and B) reports the summary statistics for tracking difference 


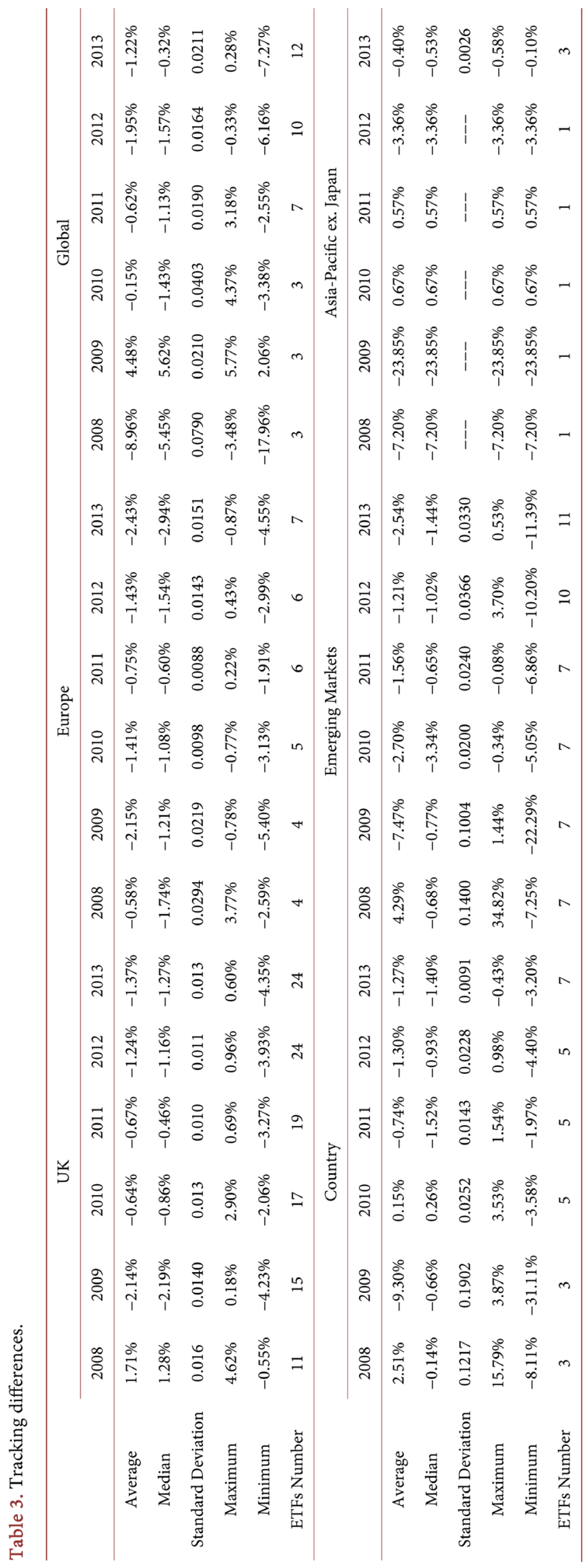


for each ETF geographical area per year. ${ }^{3}$ It should be noted that the tracking differences reported in the exhibit 5 are not adjusted for total expense ratios due to the lack of information. This is because ETFs' providers do not disclose historical expense ratios and it is not available and Datastream and Bloomberg do not provide historical expense ratios either. The average tracking differences presented as well as all other statistics should be look with cautions. This is because some ETFs in the sample outperform their benchmark indices, some ETF in the sample underperform their benchmark indices by the same magnitude. If average these values, the tracking differences appear to diffuse.

As can be seen from Table 3 (Panels A and B) that the tracking differences vary significantly across different ETFs and over sample period. In general, the ETFs in the sample underperform their benchmark indices. Remarkably, 9 out of 11 U.K. ETFs significantly outperformed their benchmark indices in 2008. At the same time, many of the global ETFs, country ETFs, emerging markets ETFs, and Asian Pacific region ETFs significantly underperformed their benchmark indices in 2008-2009. It indicates once again that the extreme market events of 2008-2009 negatively affected the ETFs' ability to replicate their benchmark indices' performance. Only two out of sixty four ETFs slightly outperform their benchmark indices in 2013 (SPDR FTSE UK All-Share UCITS ETF and Vanguard FTSE Emerging Markets UCITS ETF).

Since total expense ratio has a significant effect on the level of the ETF's tracking difference, Table 4 presents total expense ratios across different ETF's categories for 2013.

The average expense ratio across all ETFs is 0.40 . The largest value comes from emerging market ETFs (0.61). These findings are consistent with [14] and [15]. Interestingly is the fact that expense ratios for synthetic ETFs are larger than for physical ETFs, although expense ratios vary significantly across ETFs' categories.

\subsection{Daily Returns Correlation}

We next report the average correlation coefficients of the ETFs' daily returns with their benchmark indices' per year. Across all observations in the sample, the average correlation is $79 \%$ between the ETFs' and their benchmark indices' returns. However, values vary across different ETFs' categories and over the sample period. Across all observations in the sample, the highest correlation

Table 4. Expense ratios (2013).

\begin{tabular}{ccccccc}
\hline $\begin{array}{c}\text { Replication } \\
\text { Method }\end{array}$ & $\begin{array}{c}\text { United } \\
\text { Kingdom }\end{array}$ & Europe & Global & $\begin{array}{c}\text { Country } \\
\text { ETFs }\end{array}$ & $\begin{array}{c}\text { Emerging } \\
\text { Markets }\end{array}$ & $\begin{array}{c}\text { Asian Pacific } \\
\text { Region ex Japan }\end{array}$ \\
\hline $\begin{array}{c}\text { Physical } \\
\text { Synthetic }\end{array}$ & 0.33 & 0.39 & 0.37 & 0.33 & 0.41 & 0.31 \\
\hline
\end{tabular}

Values in percentage.

${ }^{3}$ Values per each ETF are available upon request. 
coefficient exhibit ETFs listed on the LSE that provide an exposure to the U.K. equity market (94\%). This correlation coefficient indicates that there is a strong linear correlation between the U.K. ETFs' and their benchmark indices' returns. It is important to note that the ETFs that track indices of non-U.K. securities exhibit noticeably lower correlation returns with their benchmark indices. Across all observations in the sample, the smallest values come from Asian Pacific region ETFs (60\%), country ETFs (64\%) and emerging markets ETFs (66\%).

These findings are consistent with the results described in the previous section that U.K. Equity ETFs show better daily tracking performance compare to non-UK Equity ETFs. A well as these findings are in line with findings of [8]. They find that the median correlation of U.S. ETFs that track indices of U.S. securities is $98 \%$. Conversely, the median correlation U.S. ETFs that track indices of non-U.S. securities is $72 \%$. The lower correlations between non-U.K. ETFs' returns and their benchmark indices' returns might be explained by difference in time zones. Difference in time zones can cause non-synchronicity between the non-U.K. ETFs and their benchmark indices.

\subsection{Regression Analysis}

As the last step in our analysis we apply equation 5 by regressing ETFs' returns against their benchmark indices' returns. All estimated betas coefficients are statistically significant at one percent level. Across all observations the average beta is 0.84 , although they exhibit significantly different values across different ETFs' categories and over the sample period. The largest betas come from U.K. ETFs (0.91) and Europe ETFs (0.88) whereas the smallest betas come from Asian Pacific region ETFs (0.70), country ETFs (0.77), and global ETFs (0.78).

Our findings are consistent with the findings of [3] [7] [8]. For example, in [8] the median beta across their sample is 0.94 . The largest values come from U.S. ETFs that provide an exposure on U.S. equity market (0.96). In contrast, U.S. ETFs that track indices of non-U.S. securities tend to have lower betas $(0.89){ }^{4}$

\section{Conclusions}

This paper investigates the tracking performance of physical and synthetic equity exchange traded funds listed (ETFs) on the London Stock Exchange (LSE) during the period 2008 to 2013. The evidence shows that the ETFs with synthetic replication do not demonstrate better daily tracking performance relative to the ETFs with physical replication. Furthermore, the average expense ratio of the synthetic ETFs is larger than the average expense ratio of the physical ETFs. These findings contradict to prior studies of physical and synthetic ETFs.

We also discovered that the financial crisis 2008-2009 had a significant impact on the ability of the ETFs to replicate the performance of their benchmark indices. Most ETFs exhibit larger daily tracking errors and tracking differences during

${ }^{4}$ Additionally, we perform difference of means test (t-test). Results show that there is no significance difference between the ETF's returns and its benchmark index's returns at a $1 \%$ confidence level. 
Table 5. Correlation matrix.

\begin{tabular}{|c|c|c|c|c|c|c|c|}
\hline \multirow[b]{2}{*}{ ETF } & \multicolumn{7}{|c|}{ Physical/Synthetic } \\
\hline & All Years & 2008 & 2009 & 2010 & 2011 & 2012 & 2013 \\
\hline All ETFs & $0.78 / 0.79$ & $0.72 / 0.70$ & $0.75 / 0.79$ & $0.79 / 0.80$ & $0.80 / 0.82$ & $0.83 / 0.83$ & $0.78 / 0.83$ \\
\hline UK & $0.95 / 0.94$ & $0.87 / 0.82$ & $0.92 / 0.93$ & $0.95 / 0.92$ & $0.94 / 0.95$ & $0.96 / 0.95$ & $0.97 / 0.98$ \\
\hline Europe & $0.78 / 0.83$ & 0.81/----- & 0.78/----- & 0.78/----- & $0.82 / 0.92$ & $0.75 / 0.86$ & $0.75 / 0.75$ \\
\hline Global & $0.67 / 0.70$ & $0.58 / 0.68$ & $0.63 / 0.62$ & $0.64 / 0.67$ & $0.71 / 0.75$ & $0.74 / 0.75$ & $0.62 / 0.67$ \\
\hline Country & 0.64/----- & 0.53/----- & 0.48/----- & 0.58/----- & 0.66/----- & 0.77/----- & $0.68 /----$ \\
\hline Emerging Markets & 0.66/----- & $0.54 / 0.62$ & $0.57 / 0.65$ & $0.56 / 0.68$ & $0.56 / 0.64$ & $0.73 / 0.70$ & $0.71 / 0.71$ \\
\hline Asian Pacific ex. Japan & 0.60/----- & 0.38/----- & 0.43/----- & 0.69/----- & 0.77/----- & 0.64/----- & $0.68 /---$ \\
\hline
\end{tabular}

Table 6. Regression analysis.

\begin{tabular}{|c|c|c|c|c|c|c|c|}
\hline \multirow[b]{2}{*}{ Physical ETFs } & \multicolumn{7}{|c|}{ Beta/Adj. S-Squared } \\
\hline & All Years & 2008 & 2009 & 2010 & 2011 & 2012 & 2013 \\
\hline All ETFs & $0.81^{* * * / 0.65}$ & $0.73^{* * * / 0.57}$ & $0.75^{\star * *} / 0.61$ & $0.80^{* * *} / 0.65$ & $0.78^{* * * / 0.67}$ & $0.87^{* * * / 0.71}$ & $0.86^{\star * *} / 0.64$ \\
\hline UK & $0.90^{* * *} / 0.90$ & $0.89^{* * *} / 0.77$ & $0.90^{* * * / 0.86}$ & $0.91^{\star * *} / 0.91$ & $0.88^{* * * / 0.90}$ & $0.92^{* * * / 0.93}$ & $0.91^{\star * \star} / 0.95$ \\
\hline Europe & $0.85^{* * *} / 0.61$ & $0.81^{* * * / 0.66}$ & $0.82^{* * * / 0.61}$ & $0.85^{\star * *} / 0.61$ & $0.86^{* * * / 0.67}$ & $0.87^{\star * * / 0.57}$ & $0.90^{\star * *} / 0.57$ \\
\hline Global & $0.75^{* * * / 0.46}$ & $0.63^{* * * / 0.34}$ & $0.65^{\star * *} / 0.40$ & $0.62^{* * * / 0.41}$ & $0.70^{* \star * / 0.52}$ & $0.80^{* * * / 0.55}$ & $0.80^{\star * *} / 0.42$ \\
\hline Country & $0.77^{* * * / 0.50}$ & $0.49^{* * * / 0.34}$ & $0.48^{* * *} / 0.31$ & $0.65^{* * *} / 0.36$ & $0.65^{* * * / 0.49}$ & $0.82^{* * * / 0.64}$ & $0.77^{\star * \star} / 0.50$ \\
\hline $\begin{array}{c}\text { Emerging } \\
\text { Markets }\end{array}$ & $0.77^{* * * / 0.45}$ & $0.52^{* * * / 0.30}$ & $0.57^{* * * / 0.32}$ & $0.55^{* * *} / 0.32$ & $0.46^{* * * / 0.32}$ & $0.91^{* * * / 0.54}$ & $0.95^{\star * \star} / 0.53$ \\
\hline $\begin{array}{l}\text { Asian Pacific ex. } \\
\text { Japan }\end{array}$ & $0.70^{* * * / 0.37}$ & $0.35^{* * *} / 0.14$ & $0.49^{* * * / 0.19}$ & $0.79 / 0.48$ & $0.84 / 0.60$ & $0.73^{* * * / 0.41}$ & $0.87 / 0.47$ \\
\hline $\begin{array}{c}\text { Years } \\
\text { Synthetic ETFs }\end{array}$ & All Years & 2008 & 2009 & 2010 & 2011 & 2012 & 2013 \\
\hline All ETFs & $0.87^{* * * / 0.67}$ & $0.83^{* * *} / 0.53$ & $0.84^{* * * / 0.67}$ & $0.83^{* * * / 0.66}$ & $0.84^{* * * / 0.69}$ & $0.90^{* * * / 0.72}$ & $0.93^{* * *} / 0.71$ \\
\hline UK & $0.92^{\star * *} / 0.88$ & $0.81^{* * *} / 0.69$ & $0.89^{* * * / 0.87}$ & $0.88^{* * *} / 0.85$ & $0.92^{* * *} / 0.90$ & $0.93^{* * * / 0.91}$ & $0.97^{* * *} / 0.96$ \\
\hline Europe & $1.10^{* * * / 0.71}$ & $---/--$ & ---/--- & $---/--$ & $1.10^{* * *} / 0.85$ & $1.19^{* * * / 0.73}$ & $1.01^{\star * *} / 0.56$ \\
\hline Global & $0.84^{* * * / 0.50}$ & $0.78^{* * *} / 0.47$ & $0.71^{* * * / 0.38}$ & $0.81^{\star * \star} / 0.45$ & $0.78^{* * * / 0.57}$ & $0.88^{* * *} / 0.56$ & $0.94^{* * *} / 0.45$ \\
\hline Country & $0.77^{* * *} / 0.50$ & $---/---$ & $---/---$ & $---/---$ & $---/---$ & $---/---$ & $---/---$ \\
\hline $\begin{array}{l}\text { Emerging } \\
\text { Markets }\end{array}$ & $0.81^{\star * *} / 0.47$ & $0.85^{\star * *} / 0.43$ & $0.80^{* * * / 0.48}$ & $0.78^{\star * \star} / 0.47$ & $0.72^{\star \star \star} / 0.42$ & $0.82^{\star * \star / 0.51}$ & $0.87^{* * *} / 0.51$ \\
\hline $\begin{array}{c}\text { Asian Pacific ex. } \\
\text { Japan }\end{array}$ & $0.70^{\star * *} / 0.37$ & ---/--- & $0.49^{* * * / 0.19}$ & ---/--- & ---/--- & ---/--- & ---/--- \\
\hline
\end{tabular}

***, ${ }^{* *},{ }^{*}$ Statistical significant for 1,5 , and 10 percent levels.

this period of time. This period of time was characterized by large bid-ask spreads, small trading volumes, and high volatility of currencies and exchange rates. All these together made the creation and redemption process costly and risky. However, even during the financial crisis U.K. ETFs exhibit lower daily tracking errors relative to non-U.K. ETFs. 
We provide evidence that the ETFs in the sample underperform their benchmark indices. More importantly, the analysis of the tracking errors and tracking differences of the individual ETFs reveals that a high level of daily tracking error does not always mean that an ETF performs poorly relative to its benchmark index. Conversely, a lower level of daily tracking error does not necessarily imply that an ETF performs well relative its benchmark index.

Overall, we claim that this research provides a significant contribution to the existing evidence on exchange traded funds and tracking performance. To our knowledge, it is the first research analysing the tracking performance of equity ETFs listed on the London Stock Exchange and for a period that involves the recent financial crisis.

The volatile market environment and depressed expected returns of the past several years have increased the use of tracker funds from investors. This research will shed light to the ETFs accuracy in replicating their benchmark returns in the second largest world financial market.

\section{References}

[1] Frino, A. and Gallagher, D. (2001) Tracking S\&P 500 Index Funds. Journal of Portfolio Management, 28, 44-55. https://doi.org/10.3905/jpm.2001.319822

[2] Blume, M. and Edelen, R. (2004) S\&P 500 Indexers, Tracking Error, and Liquidity. Journal of Portfolio Management, 30, 37-46. https://doi.org/10.3905/jpm.2004.412317

[3] Chu, P.K. (2011) Study on the Tracking Errors and their Determinants: Evidence from Hong Kong Exchange Traded Funds. Applied Financial Economics, 21, 309-315. https://doi.org/10.1080/09603107.2010.530215

[4] Johnson, B., Bioy, H., Kellet, A. and Davidson, L. (2013) On the Right Track: Measuring Tracking Efficiency in ETFs. Morningstar ETF Research.

[5] Ackert, L.F. and Tian, Y.S. (2008) Arbitrage, Liquidity, and the Valuation of Exchange Traded Funds. Financial Markets, Institutions and Instruments, 17, 331-362. https://doi.org/10.1111/j.1468-0416.2008.00144.x

[6] Johnson, T.C. (2008) Volume, Liquidity, and Liquidity Risk. Journal of Financial Economics, 87, 388-417.

[7] Shin, S. and Soydemir, G. (2010) Exchange-Traded Funds, Persistence in Tracking Errors and Information Dissemination. Journal of Multinational Financial Management, 20, 214-234.

[8] Buetow, G.W. and Henderson, B.J. (2012) An Empirical Analysis of Exchange-Traded Funds. Journal of Portfolio Management, 38, 112-127.

[9] Drenovak, M., Urosevic, B. and Jelic, R. (2012) European Bond ETFs: Tracking Errors and Sovereign Debt Crisis. European Financial Management, 20, 958-994.

[10] Pennathur, A.K., Delcoure, N. and Anderson, D. (2002) Diversification Benefits of I Shares and Close-End Country Funds. Journal of Financial Research, 25, 541-557. https://doi.org/10.1111/1475-6803.00036

[11] Maister, D., Schorr, M., Perlman, D. and Minar, S. (2010) Exchange-Traded Funds: Average Tracking Error Rose Meaningfully in 2009. Journal of Index Investing, 1, 132-163. https://doi.org/10.3905/jii.2010.1.1.132

[12] Ackert, L.F. and Tian, Y.S. (2000) Arbitrage and Valuation in the Market for Stan- 
dard and Poor's Depositary Receipts. Financial Management, 29, 71-88. https://doi.org/10.2307/3666230

[13] Svetina, M. (2010) Exchange Traded Funds: Performance and Competition. Journal of Applied Finance, 20, 130-145.

[14] Domowitz, I., Glen, J. and Madhavan, A. (2001) Liquidity, Volatility and Equity Trading Costs across Countries and over Time. International Finance, 4, 221-255. https://doi.org/10.1111/1468-2362.00072

[15] Blitz, D. and Huij, J. (2012) Evaluating the Performance of Global Emerging Markets Equity Exchange-Traded Funds. Emerging Markets Review, 13, 149-158. 